\title{
CIDADANIA E SENTIMENTO DE PERTENCIMENTO- AGENTES ATUANTES NA PRESERVAÇÃO DO MEIO AMBIENTE
}

\section{ARTIGO ORIGINAL}

MELO, Celia Regina Miranda ${ }^{1}$, PISANI, Maria Augusta Justi²

MELO, Celia Regina Miranda. PISANI, Maria Augusta Justi. Cidadania e sentimento de pertencimento- agentes atuantes na preservação do meio ambiente. Revista Científica Multidisciplinar Núcleo do Conhecimento. Ano. 06, Ed. 11, Vol. 01, pp. 167-182. Novembro 2021. ISSN: 2448-0959, Link de acesso: https://www.nucleodoconhecimento.com.br/arquitetura/cidadania-e-sentimento, DOI: 10.32749/nucleodoconhecimento.com.br/arquitetura/cidadania-e-sentimento

\section{RESUMO}

As diferentes razões que levam uma população a escolher o lugar em que irá se instalar fazem com que, de alguma maneira, esta se identifique com o local escolhido. Tendo isto em vista, se tencionou responder a seguinte questão: uma população, alheia ao espaço que ocupa, reconhece os atributos de ser cidadão e sente necessidade de preservar o meio ambiente em que vive? Diante disto, este artigo tem como objetivo discutir se uma população, alheia ao espaço que ocupa, reconhece os atributos de ser cidadão e sente necessidade de preservar o meio ambiente em que vive. Discorre, também, sobre a necessidade de criação de políticas públicas para o uso e ocupação do solo que considerem não só as questões ambientais, mas também o sentimento das pessoas e os lugares que elas ocupam. Como resultados foi constado que estudos demonstram que a conexão homem-espaço desperta a cidadania em seus habitantes. Quando estes são motivados a desocupar seu espaço para ocupar outro, ocorre o rompimento deste vínculo, sendo necessário um certo tempo para que ele novamente seja criado. A

\footnotetext{
${ }^{1}$ Doutoranda, Mestrado, Graduação, tecnólogo. ORCID: https://orcid.org/0000-0001-7720-8561

${ }^{2}$ Orientador. ORCID: 0000-0002-0467-2854
} 
consequência disso é a quebra do sentimento de pertencimento e a desmotivação à preservação dos territórios que ocupam. Demonstrou-se, também, que, quando é dada a oportunidade de fazer parte das decisões tomadas pelos gestores sobre seus territórios, na população, são instigados outros sentimentos como o de preservação do meio ambiente em que vive. Além disso, discutiu-se o desinteresse ambiental gerado pela desconexão dos indivíduos com seus espaços a partir das intervenções urbanas ocorridas. Para isso, se valeu de dois procedimentos metodológicos: levantamentos bibliográficos sobre o tema e análise de dados primários de arquivos públicos. A partir da documentação pesquisada, concluiu-se que esse envolvimento é necessário para que a preservação do meio ambiente aconteça e faça algum significado para a população que dele usufrui. Desta forma, espera-se que os resultados obtidos induzam gestores a produzir políticas públicas que envolvam a população, a partir do conhecimento dos seus territórios, objetivando a preservação do meio ambiente.

Palavras-chave: Cidadania, Intervenção urbana, Espaços públicos, Meio ambiente.

\section{INTRODUÇÃO}

O conceito de cidadania está intimamente ligado às noções de direito e dever que uma população possui. $O$ conhecimento desses preceitos está em permanente construção e têm como produto o respeito à convivência. Possibilita às pessoas expressar suas ideias e anseios em tempo real, por meio da participação, de modo direto ou indireto, na formação das cidades. A internalização desses elementos é determinante para a administração dos interesses de maneira justa e ordenada.

A cidadania está diretamente vinculada à necessidade de identificação da população com os locais onde vivem. Ser membro proativo, fazer parte do grupo e ser receptor dos benefícios atingidos faz com que as pessoas adquiram a condição de cidadãos. Desta maneira, pode-se dizer que cidadania provém da razão entre o ideal individual e os valores buscados pelo grupo a que pertence. Implica em consciência e participação para garantia do bem-estar e da qualidade de vida dos indivíduos de 
um grupo. Por meio dela, conforme destaca Lavalle (2003), através de processos longos e conflituosos, surgem os direitos civis, políticos e sociais e, em contrapartida, os deveres como cidadão. O conceito tradicional de cidadania é o descrito por Marshall (1949, p. 76):

A cidadania é um status concedido àqueles que são membros integrais de uma comunidade. Todos aqueles que possuem o status são iguais com respeito aos direitos e obrigações pertinentes ao status. Não há nenhum princípio universal que determine o que estes direitos e obrigações serão, mas as sociedades nas quais a cidadania é uma instituição em desenvolvimento criam uma imagem de uma cidadania ideal em relação à qual o sucesso pode ser medido e em relação à qual a aspiração pode ser dirigida.

A consciência sobre seus atos demonstra que os individualizados podem gerar consequências sobre toda uma comunidade. $O$ produto natural gerado por esta conscientização é o interesse e a preservação dos espaços que ocupam. A participação responsável do cidadão, nas várias esferas, precisa buscar, dentre outros, a preservação do meio ambiente em que vive. Este anseio surge desde que é entendido que sua degradação extrapola os limites do grupo, prejudicando a toda a comunidade. $O$ sentimento só aflora se este mesmo indivíduo sente que o espaço que ocupa também é seu.

Estabelecendo como base os conceitos sociais já existentes sobre cidadania, pertencimento, espaços públicos, gentrificação e requalificação, pertencentes a bibliografia especializada bem como a documentos oficiais e estudos já realizados sobre estas questões, esta pesquisa pretendeu analisar a relação estabelecida entre esses fenômenos e suas conexões com a preservação do meio ambiente, a partir da resposta à pergunta norteadora: uma população, alheia ao espaço que ocupa, reconhece os atributos de ser cidadão e sente necessidade de preservar o meio ambiente em que vive?

Tem o objetivo de discutir se uma população, alheia ao espaço que ocupa, reconhece os atributos de ser cidadão e sente necessidade de preservar o meio ambiente em que vive. Discorre sobre a necessidade de criação de políticas públicas 
para o uso e ocupação do solo que considerem não só as questões ambientais, mas também o sentimento das pessoas e os lugares que elas ocupam. Desta forma, estas farão parte, efetivamente, de processos de desenvolvimento mais sustentáveis, a partir do momento em que percebam os benefícios que a preservação do meio ambiente pode trazer para esta e as futuras gerações.

\section{PERTENCIMENTO}

Diferentes populações podem ocupar o mesmo espaço de diversas maneiras gerando implicações distintas. Tentar entender quais foram as opções e causas que conduziram a ocupar determinado território, abre caminho para reflexões sobre quais são as necessidades da população para alcançar a qualidade de vida, fator que beneficia a sustentabilidade.

Essas percepções induzem ao raciocínio que o processo de urbanização, a expansão urbana sem critérios pré-estabelecidos e o crescimento da população podem acarretar uma série de problemas sociais e ambientais nas cidades, mas o planejamento pode minimizar esses impactos-Barros e Virgílio (2003) afirmam que usualmente o processo de urbanização tem-se caracterizado pela condução da população, principalmente a de menor renda, para as periferias, provocando a substituição do ecossistema natural, por um meio completamente adverso, em que o homem organiza esse espaço segundo suas necessidades de sobrevivência e o poder que exerce sobre ele.

Para Smith (2005), esse caminho rumo à periferia é uma estratégia justificada pelo desenvolvimento urbano e um procedimento associado a projetos de regeneração espacial, que repercute em setores culturais e comerciais. Provoca a subutilização dos centros urbanos com o consequente decréscimo da população residente, causando a expansão da mancha urbana desordenadamente e o empobrecimento dos ecossistemas. 
Estas são conduzidas para os locais em que a infraestrutura urbana tarda a chegar, impedindo-as de usufruir de um ambiente urbano já estruturado. Este movimento geralmente encontra grande resistência por parte dos deslocados e causa o rompimento do sentimento de pertencimento que a população havia criado com os espaços que ocupava.

Essa sensação de pertencimento dá identidade aos espaços da cidade, e estes passam a fazer conexão com seus usuários. Neles se manifestam as trocas e relações humanas, despertando o sentimento de "cuidar para não deixar de ter".

Essa apropriação da população por seu território é importante na construção dos projetos e para que eles efetivamente aconteçam. O sentimento de estar envolvido em qualquer processo traz uma espécie de controle de seu desenvolvimento e expansão, facilitando a mobilização política, ações coletivas, prevenção à criminalidade e preservação ao meio ambiente. Além disso, contribui para a saúde mental e física dos moradores que se sentem mais acolhidos pelo lugar e, consequentemente, mais proativos.

A relação dos espaços e do meio urbano está vinculada não só ao meio natural, mas também ao construído e ao seu desenho, passando a representar, muitas vezes a imagem do lugar. Esse fato torna os locais especiais possibilitando articulações de interesses e esforços no sentido de sua preservação. Deste modo, Mendonça (2007, p. 01) diz que:

[...]encontram- se as possibilidades de uso indicadas diretamente pelo ambiente urbano construído, mas também, as possibilidades intuídas a partir dele, adaptadas às necessidades imediatas ou aos desejos e intenções não satisfeitos na construção do ambiente.

A possibilidade de usufruir dos espaços e a vitalidade gerada pelo sentimento de pertencimento, na maioria das vezes, são fatores relevantes na decisão de ocupálos ou não. A apropriação dos espaços pela população é atribuída por Santos e Vogel (1985) à "mecanismos de defesa e superação da população aos modelos urbanísticos impostos pelos planejadores". Porém, os autores reconhecem que

Link de acesso: https://www.nucleodoconhecimento.com.br/arquitetura/cidadania-esentimento 
apesar da reação da população às imposições, os projetos urbanísticos devem continuar atuando sobre as estruturas físicas. O que de fato deve acontecer é permitir que nestes, de forma mais adequada e segura, haja espaço para a participação dos cidadãos, que demonstram as suas apropriações e experiências.

\section{ESPAÇOS DE CONEXÃO}

Segundo Matos (2010, p. 18), dentre os espaços públicos formalmente construídos, os que mais são apropriados pelas pessoas são as ruas, parques e praças. Entre esses, Lamas (1993), considera a rua como o grande elemento de identificação entre a população e a cidade. $O$ autor afirma que:

[...] é um dos elementos mais claramente identificáveis tanto na forma de uma cidade como no gesto de a projetar. Assenta num suporte geográfico preexistente, regula a disposição dos edifícios e quarteirões, liga os vários espaços e partes da cidade, e confunde-se com o gesto criador. (LAMAS. 1993, p. 98)

A rua tem o poder de criar histórias e vínculos entre as pessoas que por ali circulam, define o traçado dos lugares, indica o crescimento e a formação das cidades de maneira hierarquizada, podendo ser considerada quase uma extensão de suas casas. Os moradores se apropriam desses espaços e neles estreitam relações com a vizinhança.

O mesmo ocorre com as praças que se tornam pontos de convivência e tomam funções diferenciadas às que se destinavam inicialmente. Passam a ser lugares de permanência, capazes de gerar grandes acontecimentos e manifestações da vida urbana. São indicativas da qualidade de vida de seus habitantes e inclusive da arquitetura local e dos espaços vivos. Capazes de motivar seus frequentadores, tornam-se um referencial de vida. São muito mais que alargamento das ruas ou confluência de traçados, ou ainda locais de passagens.

Exercem um papel maior do que a relação de cheio e vazio com o espaço edificado e com suas fachadas e são muito mais para a população do que o resultado de um programa ou projeto que the dá forma e funcionalidade específica. Suas 
características adquiridas conduzem à apropriação pelos moradores e se apresentam como fundamentais para a vida urbana.

Além de praças, nesse mesmo foco, poderia ser inserido na categoria dos locais que a população se apropria, outros que compõem a cidade como jardins, passeios, alamedas, canteiros e outros espaços de uso público, sendo que todos esses têm como característica as práticas sociais e possuem os espaços verdes como elementos predominantes. O que se percebe, como sendo fator comum a eles, como ressalta Lamas (2000), é a valorização do verde como evolução e requinte no modo de se viver. Possuem a capacidade de gerar novos ambientes e "recintos arborizados".

Outro importante espaço de apropriação pela população a ser considerado são os parques que apresentam componentes da paisagem natural e edificações destinadas a atividades recreativas, culturais e/ou administrativas que, na maioria das vezes, estabelecem conexão com seus frequentadores.

Esses espaços citados são objetos de apropriação pelos seus usuários e capazes de modificar os hábitos sociais existentes repercutindo sobre os demais das cidades, podendo inclusive torná-los pontos atrativos para os que não deles desfrutam no dia a dia.

Em uma escala maior, os bairros também despertam o sentimento de pertencimento por seus moradores. São conectados por meio de acordos gerados pelos anseios comuns à comunidade. Para Jacobs (2014), apropriação dos bairros ocorre quando quatro princípios básicos acontecem:

a) As ruas devem ser vivas e atraentes;

b) A malha urbana formada pelas ruas deve ser o mais contínua possível;

c) Os parques, praças e edifícios públicos são utilizados de maneira que permita a multiplicidade de usos; 
d) Há enfatização na identidade da área para que esta funcione como distrito.

Jacobs (2014), defende que os espaços só terão sucesso se fizerem parte de um contexto com diversidade de pessoas e usos e em áreas densas. Santos (1988) entende o bairro como elemento estruturador das cidades a partir da concepção de Unidade de Vizinhança. Estes teriam exatamente a função da conexão das pessoas na tentativa de formar parceiros para seu desenvolvimento por meio da sua apropriação.

O que se extrai desses autores é que o sentimento de pertencimento costuma ser estabelecido quando os equipamentos comunitários são caracterizados e localizados de acordo com as demandas dos moradores ou pelo seu convencimento, através do levantamento do existente e do desejado pela comunidade.

\section{AS INTERVENÇÕES SOFRIDAS NOS ESPAÇOS E O MEIO AMBIENTE}

sentimento de pertencimento faz com que a população se sinta capaz de sugerir projetos de modernização e intervenções visando maior desenvolvimento dos espaços urbanos, qualificando-os e trazendo apropriações inéditas. Espaços com essa natureza são comumente reivindicados pela população. Tornam-se referenciais simbólicos e condicionadores das relações sociais existentes entre eles. A apropriação dos espaços é um importante fator relacionado à cidadania. A esse respeito Souza (2002) afirma que essa apropriação é o caminho para se alcançar maior justiça social e qualidade de vida. Isso ocorre quando:

[...] os próprios indivíduos e grupos específicos definem os conteúdos concretos e estabelecem as prioridades com relação a isso, podem-se considerar justiça social e qualidade de vida como subordinados à autonomia individual e coletiva enquanto princípio e parâmetro.

Nas transformações que venham a acontecer nos espaços, é preciso que sempre seja considerada a qualidade de vida da população usuária. Estes devem sempre

Link de acesso: https://www.nucleodoconhecimento.com.br/arquitetura/cidadania-esentimento 
manter a ideia de troca, convivência e encontros, pois dessa maneira serão mantidos o bem-estar no ambiente urbano. Afinal, uma cidade saudável é composta pelo conjunto de edifícios, por seus espaços públicos e pelo meio urbano ambiental em que ela está inserida. Esse conjunto de fatores que garante que há "vida" nas cidades.

A perda do sentimento de pertencimento pela população conduz, inevitavelmente, ao abandono dos espaços. Assim, sempre que a população venha a ter seu lugar de moradia alterado por esta ou aquela razão, é preciso que este sentimento seja devolvido a ela. Em função disso, é imprescindível que se estabeleça a conexão entre gestores e comunidade, visando facilitar a implantação e aceitação de políticas públicas de urbanização. Para isso, é preciso considerar o modus vivendi da população no lugar em que esteja estabelecida.

O sentimento de preservação, respeito à natureza e desenvolvimento sustentável passa a fazer sentido para todos quando a população se apropria de forma democrática do espaço. Esse pertencimento faz com que a própria comunidade perceba os benefícios e vantagens existentes em uma parceria estabelecida com o meio ambiente.

\section{REQUALIFICAÇÃO DOS ESPAÇOS, EXPULSÃO E DEGRADAÇÃO}

As cidades são estruturas e políticas dinâmicas que se encontram em constante transformação. As mudanças ocorridas podem ser imperceptíveis e lentas ou de impacto como quando são construídas novas edificações. Mas, seja qual for o formato da mudança, a população do local nunca será a mesma. Não existe estagnação, pois mesmo que a paisagem não seja alterada, as pessoas se deslocam para outras regiões, às famílias crescem, as necessidades locais mudam. A questão não é tentar impedir essas mudanças, mas sim garantir que sejam benéficas para a grande maioria e acompanhadas de políticas públicas de infraestrutura objetivando o não agravamento dos problemas. Essas intervenções que ocorrem, necessárias ou não para o desenvolvimento urbano, são processos 
que alteram as características de um lugar, mas que levam ao que se chama gentrificação.

Para Mattos (2017), o processo de gentrificação é resultado do desenvolvimento desigual e gera resistência não só dos gentrificados, mas muitas vezes dos habitantes do espaço que os acolhe. Isso ocorre por várias razões e inclusive por diferença de classe social. De maneira simplista, define Cortright (2019), essa resistência ocorre porque "gente diferente de você muda-se para seu bairro".

Termos como renovação, revitalização ou regeneração dos espaços são usados para minimizar os efeitos causados pelo processo de gentrificação, objetivando serem mais aceitos pela população. Fato é que este é um processo que sempre implica em alterações na cidade e na vida dos gentrificados. Não cabe aqui discutir a necessidade de recuperação dos espaços, porém o processo de "empurrar" as pessoas para a periferia que causa prejuízos que afeta toda a cidade.

A descaracterização das culturas locais dos espaços construídos ao longo dos anos em benefício da sua recuperação pode trazer sua sobrevalorização, mas, na prática também pode destruí-lo, caso não haja a apropriação pelos novos usuários. Discutir se a requalificação será benéfica ao espaço foco da intervenção é um assunto a ser tratado ao longo dos anos subsequentes a ela, porém, ainda em fase de projeto, é perfeitamente possível verificar se ela é pertinente e se vem ao encontro às demandas existentes, não sendo só um tipo de clientelismo.

Além disso, o processo de requalificação dos espaços deve ponderar o grau de atratividade das suas novas funções, pois além dos imóveis residenciais, todos os estabelecimentos comerciais e serviços passam pelo mesmo processo modificando a paisagem. Porém, há de se lembrar que, conforme cita Rangel (2015), a simples elitização do local não garante o sucesso do projeto, mas sempre causará a expulsão dos habitantes de renda incompatível. Não se pode esquecer que a cidade é construída em seu cotidiano pelos atores que atuam nela. 
O grande propósito da requalificação dos espaços, na maioria das vezes, é o ganho cultural que objetiva impulsionar os investimentos e investidores aumentando a confiabilidade no sucesso do negócio, por meio da criação de consensos sobre a destinação deles. São embasadas em operações de marketing que visam sua comercialização. É o mercado imobiliário apostando nessa localidade e tentando transformá-la em uma nova centralidade urbana, enquanto ainda não é uma área visada.

A população que foi conduzida a se deslocar se instala ou em áreas rejeitadas pelo mercado imobiliário privado, ou em públicas situadas em regiões desvalorizadas como fundo de vales ou encostas íngremes, terrenos sujeitos a inundações ou escorregamentos, regiões poluídas ou áreas de proteção ambiental onde a vigência de legislação de proteção e ausência de fiscalização definem suas desvalorizações.

Segundo Maricato (2003), a tolerância pelo Estado em relação à ocupação ilegal por parte das populações de baixa renda que acontece nessas regiões e que quase sempre é predatória às áreas de proteção ambiental ou demais áreas públicas, não pode ser considerada como uma tentativa de auxílio aos carentes de moradia ou aos direitos humanos.

Essa população, mesmo que involuntariamente, compromete os recursos naturais existentes nessas regiões periféricas, fundamentais a todos os moradores da cidade. Exemplo disso são os mananciais de água, que são costumeiramente usados para despejo de esgotos clandestinos. Não é por opção que elas se instalam nesses locais, já que frequentemente esses locais não fornecem acesso aos serviços públicos e infraestruturas. A elas não restam opção, pois a vida em outras regiões mais bem aparelhadas se torna inviável economicamente.

Essas mudanças dos espaços construídos que ocorrem em suas vidas, resultam na perda do sentimento de preservação da natureza, a ponto de não perceberem que os recursos naturais compõem os bens que consomem. 
Contraditoriamente, com o passar do tempo, quando essas mesmas populações desenvolvem o sentimento de pertencimento a estas novas áreas, muitas vezes se deparam com outra questão: uma relação conflituosa com o Ministério Público. Passam a novamente lutar para permanecer nestes locais, mesmo sendo irregulares. Essa situação, muitas vezes é apoiada por parlamentares clientelistas que, ao cabo, são insensíveis às questões sociais e ambientais. Essa dinâmica é um cenário frequente e resultante de ocupação ilegal de áreas de preservação.

Percebe-se que não há instrumentos que façam a interação entre esses projetos que envolvem os ambientes urbanos, meio ambiente e a realidade de seus habitantes.

A gestão urbana de fato tem grande dificuldade em incorporar ao orçamento público a necessidade da massa moradora da cidade ilegal e de mandatária de vários serviços e a necessidade de preservação do meio ambiente. $O$ desconhecimento dessas realidades é amenizado por ações pontuais definidas quase sempre em barganhas políticas.

No âmbito da gestão das cidades, existem políticas urbanas que contribuem para os processos de gentrificação. Exemplo disso são as chamadas Operações Urbanas que podem privilegiar os interesses dominantes e a lógica da especulação imobiliária, reproduzindo a exclusão socioeconômica e a privatização da esfera pública. Estas se apresentam sempre com a oficial finalidade de recuperação de áreas degradadas, tornando-as atraente para investidores.

Além disso, mesmo as iniciativas ecológicas que criam ou restauram áreas que possuem a necessidade de serem "esverdeadas" também expulsam a população de baixa renda ocupante dessas áreas: a chamada gentrificação verde. Esses atingidos fazem parte de grupos com maior privação socioeconômica e sem poder de decisão.

Em resumo, essas populações deslocadas são colocadas em territórios vulneráveis ou considerados degradados e consequentemente os que mais sofrem com os 
impactos ambientais produzidos. Não podem ser considerados cidadãos, pois são privados dos requisitos mínimos para isso.

\section{OS CONDOMÍNIOS FECHADOS}

Em contraponto, existe o crescimento dos condomínios fechados que também vão se instalar nas periferias das cidades, em locais ainda desabitados e próximos da natureza. Estas regiões recebem moradores de classe média alta que buscam terrenos maiores e espaço para suas moradias em verdadeiras fortalezas equipadas por todo tipo de lazer sendo, muitas vezes, separados das classes sociais mais baixas por muros ou outros aparatos de tecnologia.

Essa situação eleva o custo da terra na periferia, pois a ocupação por estes habitantes de maior poder aquisitivo agrega valor aos terrenos e traz infraestrutura para a região, assim como comércio e serviços de qualidade.

Isso demonstra que nem sempre o processo de ocupação da periferia pela população expulsa ou produzida é negativo. Estas podem trazer urbanidade para os lugares muitas vezes esquecidos pelos gestores e passando a ser "o motor para a redefinição do urbano". (INGELS, 2018, n.p.)

Essas ocupações periféricas por condomínios oferecem atrativos aos grupos interessados em investimentos nessas regiões. Criam infraestrutura proporcionando benefícios para atender aos novos habitados que optam por usufruir da paisagem natural.

Como afirma Levy (2010) os condomínios fechados conciliam habitação com qualidade de vida, conforto e segurança, espaço e lazer. Além disso, pessoas que escolhem viver nesse tipo de habitação, valorizam a vida entre os que compartilham desses mesmos valores, longe de interações indesejadas. Este fato produz um ambiente onde as relações entre o público e o privado são alteradas. Produzem espaços de acesso exclusivo, reduzindo a possibilidade de convivência e gerando, em última análise, o abandono dos espaços públicos externos a ele como ruas,

Link de acesso: https://www.nucleodoconhecimento.com.br/arquitetura/cidadania-esentimento 
praças e parques, sendo estes, muitas vezes, tomados, em contrapartida, pelos excluídos e de baixa renda.

Essas aprazíveis regiões periféricas deixam de ser desprezadas e se tornam alvo dos investidores do mercado imobiliário para a construção de grandes empreendimentos. A disponibilidade de espaço e o preço dos terrenos são algumas das razões para isso. Além do eixo Rio-São Paulo, existem vários exemplos dessas privilegiadas regiões periféricas, como é o caso de Alter do Chão, Pará, considerado - Caribe brasileiro, que se localiza a $30 \mathrm{~km}$ de Santarém, sendo refúgio principalmente de turistas internacionais.

Observa-se que a transformação na paisagem dessas bordas periurbanas das cidades vem se acentuando em função dos interesses de ordem política, econômica e social, sendo o uso indiferenciado do solo pela iniciativa privada, uma das possíveis causas da expansão urbana sobre áreas de interesse e proteção ambiental.

Pelo pouco valor da terra, também se instalam nas periferias, condomínios destinados aos habitantes de baixo poder aquisitivo. Estes condomínios, apesar de atender uma população de baixa renda, são diferentes dos grupos que se instalam de maneira informal nas periferias. Apoiados por políticas públicas de habitação trazem a formalidade a muitos locais periféricos das cidades.

Mas, também essa iniciativa pode levar a degradação do ambiente natural principalmente porque, muitas vezes, a aprovação destes condomínios nesses locais se dá para atender interesses de alguns grupos que não possuem a preocupação de integração de políticas urbanas e de meio ambiente. Essas aprovações nem sempre estão de acordo com os interesses da população como um todo e sim de um grupo seleto.

O sentimento de pertencimento e de preservação ambiental dos novos moradores que se instalam nessas regiões só surge com o passar do tempo, pois estes são produtos da citada exclusão. De imediato, só sentem a mudança que ocorreu em 
suas vidas e não estão preocupados com o que existia na região antes de sua chegada.

Considerando o aspecto ambiental, segundo Corellano (1998), essas regiões periurbanas são detentoras da justaposição e coabitação de três tipos de espaços:

a) Espaços naturais: predominantemente verdes, são áreas ou desabitadas, ou com baixa densidade demográfica, tem importante valor ecológico;

b) Espaços rurais: predominantes usos agrário, pecuário e florestais, com núcleos populacionais existentes e de baixa densidade. Sua função é produzir alimentos e matérias-primas. Entretanto, na medida em que a agricultura sofre transformações por meio das inovações tecnológicas provocam mudanças na paisagem rural e agressões ao meio ambiente;

c) Espaços urbanos: compostos por bairros periféricos, com residências, instalações turísticas, distritos industriais, grandes infraestruturas urbanas, entre outros. Tem interferência antrópica e provoca grande degradação ambiental.

As regiões periurbanas tem despertado, cada vez mais o interesse do mercado imobiliário, sendo alvo de grande especulação pelos incorporadores que investem na transformação deles visando lucro futuro.

A preferência por estas regiões por um grupo de pessoas não acontece por acaso. Dentre outros aspectos, este leva em conta alguns fatores: a aproximação com a natureza, a maior homogeneidade da vizinhança a qual se enquadra no mesmo padrão de vida e o prestígio social. Essa tendência de serem criados condomínios localizados em regiões periurbanas destinados a uma classe que tem maior poder aquisitivo foi resultado de uma transformação sofrida ao longo do tempo, em razão de mudança de valores e costumes, pois anteriormente estes residiam próximo ao centro, onde Ihes era dado o acesso aos serviços, infraestruturas e equipamentos coletivos. 
O aparecimento desses condomínios proporciona a difusão dos serviços, até então localizados nas áreas centrais das cidades, em função da necessidade de atender esses novos moradores mais exigentes, modificando a configuração espacial das regiões.

$\mathrm{Na}$ implantação dos condomínios fechados o poder público tem importante papel, pois é ele que viabiliza a criação de condições de infraestrutura para atendê-los. Um exemplo disso é o estabelecimento de ruas ou rodovias de acesso e integração com os demais espaços da cidade. A provisão de infraestrutura, serviços urbanos, condições de acessibilidade realizadas ao redor desses loteamentos agregam valor a eles.

Muitas vezes, os investidores adquirem glebas de terra próximas a estes condomínios e ficam à espera de que o desenvolvimento da cidade se encarregue de valorizá-las sem que nenhum investimento seja feito pelo proprietário: os chamados terrenos de engorda (SABOYA, 2008, p. 02). Este comportamento não contribui em nada para as cidades, pois não gera emprego, não presta nenhum serviço e traz prejuízos para a sociedade.

Ocorre ainda, o processo inverso em algumas regiões periurbanas: uma localização considerada "ruim" é valorizada, pois, a seu lado é implantado algo pior. Então, quanto mais distantes destes novos locais considerados "piores", mais valorizados serão os outros terrenos. Explica Saboya (2008) que "quando um terreno deixa de ser uma das piores localizações, pela adição de novas "piores localizações", seu preço sobe automaticamente". Atividades poluidoras ou ainda determinados tipos de edificações autorizadas pelas administrações dos municípios podem gerar esse processo.

\section{CONSIDERAÇÕES FINAIS}

Essas constatações evidenciaram que as regiões periféricas não são apenas dos gentrificados, mas também de uma elite emergente que tem um "estilo de vida" tido 
como sendo ideal: próximo ao verde, seguro e de conforto. Além disso, nota-se também que o sentimento de pertencimento que é desenvolvido pelos locais periféricos de moradia poderá conduzir novamente a redescoberta da cidadania pelos novos moradores, seja qual for o grupo social a que pertençam.

O tempo pode se encarregar de redefinir a identificação com os espaços pelos gentrificados, reconectando-os com a nova realidade, mas até que isso aconteça, as perdas são percebidas. Ideal seria que o meio ambiente não sofresse com as baixas de interesse e que os danos ambientais causados pelo abandono, degradação ou devastação não fossem irrecuperáveis. O que se observa é que a natureza, na maioria das vezes, responde a esta indiferença de alguma maneira.

Além disso, a população que se instala nesses condomínios na periferia, também precisam criar vínculos com as paisagens além muros. Desta maneira, também se tornam responsáveis pela sua preservação. Para isso, as políticas públicas criadas para essas regiões precisam envolver as diferentes questões existentes, que vão desde a solução das carências dos menos favorecidos até as necessidades dos condomínios já instalados.

Infere-se também dessas reflexões que, em função da nova ocupação da periferia e consequente expansão dos centros urbanos, existe a carência de uma política de desenvolvimento urbano ambiental que tenha um olhar mais apurado às áreas periurbanas naturais ou preservadas. Além disso, a omissão do Estado quanto a sua obrigação de garantir o direito de um ambiente ecologicamente equilibrado à sociedade, com funções e serviços ambientais necessários ao bem-estar da população, em detrimento do crescimento econômico que, em muitos casos, só beneficia a uma pequena parcela da sociedade (SOUZA, 2013, p. 8), muito contribui para potencializar os problemas.

Este estudo respondeu à questão norteadora desde o momento que concluiu que, seja qual for a nova ocupação das regiões periféricas, estas necessitam que sejam elaborados projetos embasados em critérios já estabelecidos nas políticas públicas 
de preservação do meio ambiente, pensados a partir do pleno conhecimento dos territórios e que incorporem o sentimento de pertença existente nas populações.

Projetos que tenham essas premissas apresentam maior probabilidade de obter sucesso e engajamento dos envolvidos. Serão mais internalizados, se criados a partir de parâmetros fundamentados no respeito à população e na manutenção da qualidade de vida. Este é um conceito que deve ser construído por fatores advindos do dia a dia das pessoas e que podem resultar em uma rede de fenômenos e situações associados ao sentimento de "fazer parte".

\section{REFERÊNCIAS}

BARROS, Mirian Vizintim Fernandes; VIRGíLIO, Haroldo. Praças: espaços verdes na cidade de Londrina. Revista Geografia, Londrina, v. 12, n. 1, p. 533-544, 2003. Disponivel em: http://www.uel.br/revistas/uel/index.php/geografia/article/view/67 13/6057 Acesso em: 22 jan. 2021

CORELLANO, Francisco Pellicer. El ciclo del agua y la reconversión del paisaje periurbano en las ciudad de la red C-6. In: MONCLÚS, F. J. La ciudad dispersa Suburbanización y nuevas periferias. 1998. Barcelona: Centre de Cultura Contemporània de Barcelona.

CORTRIGHT, Joe. Tudo o que causa a gentrificação, de A a Z. In: ROMULLO Baratto. Tudo o que causa a gentrificação, de A a Z. ArchDaily Brasil. 06 Set 2020. Disponível em: https://www.archdaily.com.br/br/924281/tudo-o-que-causa-agentrificacao-de-a-a-z . Acesso em: 22 fev. 2021.

INGELS, Bjarke. Gentrificação não é só negativa, também é o motor para a redefinição do urbano. El País Semanal. Brasil, jun. 2018. Disponível em: https://brasil.elpais.com/brasil/2017/10/23/eps/1508709954_150870.html Acesso em: 22 jan. 2020. 
JACOBS, Jane. Morte e Vida de Grandes Cidades. São Paulo: WMF Martins Fontes, 2014.

LAMAS, José Manuel Ressano Garcia. Morfologia urbana e desenho da cidade. Fundação Calouste Gulbenkian, 1993.

LAVALLE, Adrián Gurza. (2003). Cidadania, igualdade e diferença. Lua Nova: Revista de Cultura e Política, São Paulo, v. 59, p. 75-93. Disponível em: http://www.scielo.br/scielo.php?script=sci_arttext\&pid=S010264452003000200004\&lng=en\&nrm=iso>. Acesso em: 13 Mar. 2021.

LEVY, Dan Rodrigues. Os condomínios residenciais fechados e a reconceitualização do exercício da cidadania nos espaços urbanos. Revista ; Ponto e Virgula: Revista de Ciências Sociais do Programa de Estudos Pós Graduados em Ciências Sociais da PUC-SP. São Paulo, no 7, 2010. Disponível em: https://revistas.pucsp.br/index.php/pontoevirgula/article/view/13992 . Acesso em: 02 Fev. 2019.

MARICATO, Ermínia. Metrópole, legislação e desigualdade. Estud. av., São Paulo v. 17, n. 48, p. 151-166, Aug. 2003 . Disponível em: https://www.scielo.br/scielo.php?script=sci_arttext\&pid=S0103-40142003000200013 Acesso em: 15 mar. 2021.

MATOS, Fatima Loureiro de. Espaços públicos e qualidade de vida nas cidades - o caso da cidade Porto. Observatorium: Revista Eletrônica de Geografia, Porto, v.2, n.4, p.17-33, Jul. 2010. Disponível em: http://www.observatorium.ig.ufu.br/pdfs/2edicao/n4/Espacos_publicos.pdf. Acesso em: 05 set. 2021.

MENDONÇA, Eneida Maria Souza. Apropriações do espaço público: alguns conceitos. Estudos e Pesquisas em Psicologia, UERJ, Rio de Janeiro, ago. 2007, p.296-306, v.7, n.2. 
MARSHALL, Thomas Humphrey. Cidadania, classe social e status. Rio de Janeiro: Zahar 1967. Disponível em: https://edisciplinas.usp.br/pluginfile.php/999642/mod_resource/content/1/MARSHALL $\% 2 \mathrm{C} \% 20 \mathrm{~T} . \% 20 \mathrm{H} . \% 20 \mathrm{Cidadania-Classe-Social-e-Status.pdf.} \mathrm{Acesso} \mathrm{em:} 13$ mar. 2021.

MATTOS, Talita Vieira. Gentrificação e Humanização: Um Desafio para a Cidade de São Paulo. 2017. Trabalho de Conclusão de curso (Especialização)Universidade de São Paulo, São Paulo, 2017.

SANTOS, Carlos Nelson F. dos. A cidade com um jogo de cartas. São Paulo: Projeto, 1988.

SOUZA, Marcelo Lopes. Mudar a cidade: uma introdução crítica ao planejamento e à gestão urbanos. Rio de Janeiro: Bertrand Brasil, 2002.

SMITH, Neil. The new urban frontier - Gentrification and the revanchist city. Nova York: Routledge, 1996

SMITH, Nikaia. El redimensionamiento de las ciudades: la globalización y el urbanismo neoliberal. In: HARVEY, David. e SMITH, Neil. (eds.). Capital financiero, propiedad inmobiliaria y cultura. 2005. Barcelona, Universitat Autònoma de Barcelona.

SABOYA, Renato. O que é especulação imobiliária?. In: Urbanidades, Urbanismo, Planejamento Urbano e Planos Diretores, 2008. Disponível em: http://urbanidades.arq.br/2008/09/o-que-e-especulacaoimobiliaria. Acessado em: 20 agosto de 2021

SOUZA, Leny Cristina Barata., \& FARIA, Ivani Ferreira de. (2013). Serviços Ambientais (REDD) na RDS do Juma-Am e a Ordem Ambiental Global: entre a Racionalidade Ambiental e o Capital Fictício. Revista geonorte, Amazonas, v. 4, n 
13, p. 79 - 109. Disponível em: https://www.periodicos.ufam.edu.br/index.php/revistageonorte/article/view/1145. Acesso em: 22 fev 2021

Enviado: Outubro, 2021.

Aprovado: Novembro, 2021. 